\title{
Proceeding
}

Supplementary Issue: Spring Conferences of Sports Science. Costa Blanca Sports Science Events, 19-20 June 2020. Alicante, Spain.

\section{Teachers and burnout: Biodanza SRT as embodiment training in the development of emotional skills and soft skills}

\author{
ROBERTA ROSA ${ }^{1}$, GIUSEPPE MADONNA ${ }^{2}$ \\ 1/UL Telematic University, Italy \\ 2University of Naples "Parthenope", Naples, Italy
}

\begin{abstract}
The exposure to high stress conditions has led to an increasing prevalence of Burnout among teachers; this is due to emotional exhaustion, depersonalization and reduced personal accomplishment. Soft Skills play an important role in working performance, representing the set of emotional skills capable of promoting personal well-being. Giving priority to emotional support enables the development of protective factors and positive skills to counteract work-related stress and the onset of Burnout. Biodanza SRT is a body-mediated system that, through an Embodiment Training, promotes the development of personal empowerment by strengthening emotional skills, Soft Skills and the acquisition of Best Practices making individuals able, capable and competent in the personal management of tools and strategies to improve their emotional, affective, relational, social and professional life.
\end{abstract}

Keywords: Teachers; Burnout; Soft skills.

\section{Cite this article as:}

Rosa, R. \& Madonna, G. (2020). Teachers and burnout: Biodanza SRT as embodiment training in the development of emotional skills and soft skills. Journal of Human Sport and Exercise, 15(3proc), S575-S585. doi:https://doi.org/10.14198/jhse.2020.15.Proc3.10

Corresponding author. IUL Telematic University, Italy.

E-mail: robertarosa68@gmail.com

Supplementary Issue: Spring Conferences of Sports Science. Costa Blanca Sports Science Events, 19-20 June 2020. Alicante, Spain.

JOURNAL OF HUMAN SPORT \& EXERCISE ISSN 1988-5202

(c) Faculty of Education. University of Alicante

doi:10.14198/jhse.2020.15.Proc3.10 


\section{INTRODUCTION}

The flow of reforms that has changed the Italian school in the last twenty years has unfortunately favoured the depersonalization of the educational function, requiring teachers to carry out tasks that go beyond the mere educational relationship; they have to deal with a demanding school organization purely oriented towards efficiency, thus increasing Burnout levels among them.

Burnout is a psychological syndrome resulting from a condition of prolonged and intense work-related stress, causing a psychophysical and emotional breakdown characterized by three main dimensions: emotional exhaustion and physical fatigue, depersonalization and reduced personal accomplishment (Maslach, 1982) followed by demotivation, inner emptiness, disinterest and a sense of ineffectiveness for the work activity with reduced productivity.

The term Burnout (meaning being frustrated, exhausted), originally adopted in sports to indicate the phenomenon with which an athlete who, after years of success, would run out of energy and be no longer competitive, is currently used in working environments when even the most important, significant and exciting work, over time, can become unpleasant, unfulfilling and meaningless. The energy released daily gradually decreases, leaving room for a sense of emptiness; involvement turns into indifference and effectiveness turns into inefficiency. This, in short, is what could happen to a teacher when affected by Burnout.

Teachers are constantly confronted with a myriad of sources of stress related not only to the educational relationship (learning difficulties of their students and their aggressive behaviour, large classes, students with a wide range of Special Educational Needs) but also to problems caused by the relationship and conflict with their colleagues and students' parents, lack of social support and autonomy, poor correspondence with expectations, limited career opportunities, falling self-esteem, feeling of helplessness and failure, precariousness, poor social recognition of this profession, continuous school reforms, workload, low salary and continuous demand for professional updating that often does not meet their needs.

This scenario, therefore, leads to a teacher profile with a high risk of stress, dissatisfaction, work demotivation and Burnout, which, even in a mild form, has heavy repercussions both on the health of the teachers themselves (with a consequent increase in social costs and public health expenditure), both on the quality of the educational relationship and relational climate within the class (generating a chain of negative effects on the school, emotional and personal training of the students), as well as on the relationship between colleagues, managers and parents (giving rise to further critical issues related to isolation and lack of collaboration, outbreak of conflicts, and ineffective communication).

In recent years, almost homogeneously in schools at all levels, a growing diffusion of relational discomfort and Burnout among teachers has been observed, pointing out that their vulnerability is due to the peculiarity of a profession developing within a relationship with strong emotional value, driven by ideal motivations (conveying culture, providing educational models to young people, contributing to their formative and personal growth, and so on). These motivations are often put to the test, at least in the Italian school, by the loss of the social prestige inherent in its role, as well as by the increasing complexity of the multidimensional nature of the teaching profession (relationship with students, families, conflicts between colleagues), the many reforms and the increase in precarious employment conditions.

For this reason, it is essential to foresee prevention interventions not only for the cognitive detection of the Burnout phenomenon and the monitoring of the teachers' health and well-being state, with respect to the 
incidence and/or risk of Burnout, but above all for potential interventions to be implemented, aimed at improving the quality of relational life in schools.

It becomes fundamental to structure, within school and educational contexts, interventions aimed at increasing personal resources that develop the ability to recruit those protective factors within people, useful to make them effectively manage their own health and well-being.

In order to be able to live well, compete and excel in today's schoolwork world, it is important to hold the socalled Soft Skills and Hard Skills (technical and cognitive skills), together with strategies to be able to develop, change and increase them.

The Biodanza SRT System, through an Embodiment Training, offers experiential laboratories lived in groups that, by means of the learning-by-doing approach, the use of music, emotional movement, encounters and vivencia, constantly leads people to live their own body, encouraging the contact with themselves (identity, self-esteem, self-efficacy), the relationship with others and with the context (creating empathic networks, ecological communication based on active listening and conflict mediation), the development of one's own resources management and tools from which to draw those protective factors useful to preserve one's own and others' well-being.

Continuous training focused on the development of skills that are increasingly essential and important in the world of work, and implemented through innovative laboratory methods, makes it possible to create an ecosustainable school life, by developing everyone's human potential and stimulating teachers to promote their own well-Being, with the aim of teaching better.

"We are living in a time in which everyone's future prospects depend on their own ability to manage themselves and their relationships effectively" (Daniel Goleman,1998).

\section{TEACHING PROFESSION AND BURNOUT}

Following the European Council's Europe 2020 education policy guidelines, each State was required to focus on improving the quality and effectiveness of education and training, in order to "ensure high quality teaching, provide adequate initial education for teachers and continuous professional development for teachers and trainers, and make teaching an attractive career choice".

Continued and rapid legislative changes to which teaching staff must adhere, increased workload, perceptions of the loss of prestige of the teaching profession and inadequate financial reward, mean that teaching is not an attractive career choice.

Currently, teachers are required to have skills and competences that go beyond the didactics, but they also involve skills and competences related to the meaningful construction of educational relationships with students, colleagues, managers, and students' parents.

The teaching profession is strongly exposed to Burnout Syndrome as it is considered a Helping Profession, just like that of professionals working in contact with suffering people (doctors, nurses, psychologists), which are subject to constant stress events and at risk of exhaustion. The Burnout syndrome, involving the whole person, is the response to chronic and assiduous emotional stress characterized by physical and emotional exhaustion. 
Scientific data show that, among Italian teachers, the increase in emotional exhaustion and Burnout level is directly proportional to the increase in working years, but is also related to the lack of collaboration and adequate support by colleagues and managers, the work to be carried out in too many and difficult classes, complicated relationships with families, too much bureaucracy (Vianello, 2019), and the loss of social respect for the teachers' work.

The teacher is required to take on different roles: in addition to being an expert in teaching, he or she must also be a psychologist, an educator, a social worker, a pedagogist and a substitute parent. Therefore, he or she should teach, educate, socialize and promote the functional development of the student's personality, in addition to being able to manage relationships with colleagues, the school manager, parents and anyone who comes into contact with the school, becoming a concrete and easily reachable target on which to pass the buck to an entire inefficient school system.

The ambiguity and the multiplicity of roles that the teacher is forced to manage (often incompatible with each other), in addition to didactics and the teaching activity (preparation of lessons, correction of homework, meetings, encounters with parents, extracurricular activities and projects, interaction with students), involve a high workload and an investment on an emotional and psychological level that is not limited to class hours, and can then trigger stress or lead into the Burnout spiral.

Unfortunately, teachers are not always sufficiently trained in relational, communication and emotional management techniques. It is therefore easy to trigger the inability to adapt to rapid and continuous changes in methods and didactics, to excessive emotional involvement in the management of one's work and relationships, to the monotony of work and, no less important, to a sort of identity crisis due to a substantial lack of basic training in soft skills (emotional, cognitive and social), communication and relational strategies.

A lack of gratification due also to the adverse attitudes of colleagues, managers, parents and students, creates a real role conflict with related relational difficulties that, if not solved and turned into chronic, makes the workplace full of frustration, fear, anger, anxiety and lack of respect. This makes it unlikely that people would help each other in times of difficulty.

The Burnout syndrome indicates a mismatch between what people are and what they have to do, and expresses a deterioration that affects people's values, dignity, spirit and will, in other words, a corrosion of the human soul (Maslach, 1982).

When the teachers are working in a situation where the demands are higher than what they can actually provide, offering less than what expected from them, they begin to feel overworked, devalued, and unable to control the work performed. This leads them into a form of defensive pathological adaptation, characterized by a state of chronic exhaustion, lack of empathy, cynicism, physical and psycho-emotional detachment and disconnection from work, diminished socialization leading to difficulties in work performance, interpersonal relationships and emotional behaviour from which, in turn, there are repercussions on their working activity (both with reference to their relationship with students and educational activity, and to the didactic aspect).

An individual pathology that damages the subject's psychophysical health causes the failure to achieve organizational objectives which, in the long term, risks being harmful also for the organization in which the pathological subject operates, resulting in high rates of absenteeism and early retirement too. 
Among the physical stressors, further emerging data concern the clear structural precariousness due to the acknowledged decline of Italian schools, the lack of availability of spaces and equipment, together with the precariousness of the Italian social situation in which there is a psychological-social climate characterized by disorientated, indifferent and cynical behaviour, marked by adaptive passivity and strong self-referentiality.

It seems therefore clear and urgent that, alongside the need for structural adaptations of school buildings, it needs to carry out processes of humanization and re-humanization not only of contexts, but above all of relationships, since the working environments and the relationships developed within them tend to educate, albeit informally and unintentionally.

It is fundamental that education and training are implemented in a breeding ground characterized by the promotion of well-being in both the facilities and within their operators; this should be done in order to favour not only an adequate organizational climate, but also the ability of all the school staff to implement effective and ecological forms and interventions, facilitating collaborative work in the face of competition or lack of interest among teachers.

Organizational well-being is a multidimensional construct capable of promoting and maintaining the physical, psychological and social well-being of workers, and of influencing work processes at individual, group and organizational level.

Through appropriate training, starting from continuous active training as a professional "training ground", it is necessary to strengthen teachers' personal strategies (coping, resilience, empowerment) by developing the emotional skills underlying soft skills. These are aimed at facing and overcoming the moments of depression and discouragement characterizing all educational professions, and should help prevent and fight psychosomatic diseases, related stress and Burnout syndrome, in order to regain the meaning of the teachers' profession and their being in the world.

\section{THE THEORETICAL CONSTRUCT OF BURNOUT}

Burnout is defined as a syndrome characterized by emotional exhaustion, depersonalization and reduced personal accomplishment, which can occur in those who work in direct contact with people (Maslach, 1982) due to intense emotional and motivational involvement.

It is a response to chronic emotional stress from which a physical and psychological exhaustion is generated, a cold and depersonalized attitude in the relationship with others and a feeling of inadequacy to the tasks to be performed, combined with physical disorders, frustration, behavioural and relational problems too.

The three-dimensional model on Burnout Syndrome, worked out by Maslach (1982), highlights its manifestation through three main factors:

- Emotional exhaustion and fatigue, understood as a dysfunctional adaptive response to excessive demands due to the contact with people, in which the individual feels overwhelmed and fails to regain emotionality. This dimension is linked to psychophysical and emotional well-being more than the others, characterized by emotional overload, inability to accept new emotions, lack of energy, frustration or tension.

- Depersonalization and cynical attitude, characterized by a detached and lethargic attitude in interpersonal relationships, together with a cold indifference also towards the work itself, as well as estrangement from the relationship with the other, and distance from personal involvement in 
relationships with others through a process of de-humanization, expressed by treating others as objects.

- Lack of personal accomplishment, due to a feeling of frustration from which stems a decrease in motivation for success, a sense of inadequacy in which self-esteem diminishes. It is the feeling of effectiveness of one's work, competence and self-esteem, or even (depending on the positive or negative side) feelings of lack of confidence in one's own abilities and general inadequacy.

More recently, Folgheraiter (1994) has introduced a fourth element described as reduced self-control, or the loss of that critical sense allowing the working experience to be given the right dimension. As a result of a reduced self-control, the profession ends up taking on a disproportionate importance, leading the individual to no longer be able to mentally release himself or herself by dealing with emotional, impulsive and violent reactions too.

Stress can be considered an essential ingredient of our daily life, both at home/within the family context and in the workplace. In addition, it also brings positive effects: being a stimulus to the action, it is above all the individual ability to adapt to it (reactivity) that enables the subdivision of episodes into distress (harmful stress) and eustress (positive stress).

One or more stress conditions, if particularly intense or prolonged in time, can lead to Burnout syndrome characterized by particular moods (anxiety, irritability, tiredness, fatigue, asthenia, panic, agitation, guilt, negativism, reduced self-esteem, empathy, listening skills, and others), somatization (migraine, sweating, insomnia, organic disorders, and others) and behavioural reactions (frequent absences or delays in the workplace, defensive closure to dialogue, emotional detachment from the interlocutor, reduced creativity, and adoption of stereotypical behaviour).

While stress can be defined as a state of activation enabled by the organism when dealing with an unforeseen situation (whether positive or negative), Burnout is the result of a lack of stress management from which the condition of being stressed is generated, without a way out.

The psycho-physical and emotional wear and tear keeps increasing and, even when the stress reaches high levels (in which one burns out), the Burnout Syndrome makes the subject unable to easily realize he/she is affected by it.

\section{FROM BURNOUT TO TEACHERS' WELL-BEING, THROUGH THE DEVELOPMENT OF EMOTIONAL SKILLS AND SOFT SKILLS}

To counteract the onset of Burnout it is important to possess and develop the so-called soft skills, which are linked to emotional intelligence and that have the peculiarity of being modified, developed and learned.

When we speak of skills in the workplace, we distinguish between Hard Skills, knowledge and technical skills applicable to a given task, and Soft Skills: those relational skills and personal characteristics of an individual applicable in the interpersonal relationships, more related to what we are rather than what we know, and representing a person's working style (the way he or she performs the assigned tasks and role). It is the personal style that makes everyone unique, regardless of his or her knowledge and qualifications (Hard Skill).

The World Health Organization in its Skills for Life (1993) policy document defines Soft Skills as "a dynamic combination of cognitive and meta-cognitive skills, interpersonal, intellectual and practical skills. Soft skills 
help people to adapt and behave positively so that they can deal effectively with the challenges of their professional and everyday life".

Therefore, in the workplace, in addition to communication skills or the ability to relate to others and collaborate with them, personality traits and other characteristics denoting the ability to manage oneself and to deal with situations in an appropriate, responsible and professional way are very important too.

Developing Soft Skills means acquiring those skills that lead to positive and adaptive behaviour, enabling the individual to effectively face the demands and challenges of everyday life and turning knowledge, attitudes and values into real skills, making him or her able to know what to do and how to do it.

By contributing to perceiving self-efficacy, self-esteem and self-confidence, Soft Skills play an important role in promoting well-being, by increasing motivation to take care of oneself and others in order to prevent discomfort and health and behavioural problems.

Soft Skills can be divided into three categories: personal, social, and methodological skills. More in detail:

1) Personal Skills include all the skills that distinguish each individual: self-awareness, emotion management, self-control, optimism, resilience, motivation, flexibility/adaptability, self-reflection, selfconfidence, and strong feeling of initiative.

2) Social skills indicate the ability to establish interpersonal relationships and to possess communication skills, empathy, effective communication, effective relationships, conflict management, teamwork and leadership spirit.

3) Methodological Skills are among the most immediate professional skills, and are expressed as specific skills: autonomy, problem solving, stress management, decision-making, critical thinking and creative thinking, result orientation, planning and organization.

The Soft Skills for personal effectiveness develop gifts such as creativity and balance, fundamental factors in the work environment and necessary for solving problems even in case of static tasks.

Relational skills increase the ability to work in a team and cooperate to achieve goals. Among them, ethics and tolerance make it possible to manage stress caused by dysfunctional relationships, and to adopt behaviours appropriate to shared norms and values.

Another crucial aspect is the ability to make decisions and negotiate, which improves through the development of flexibility, empathic listening and rational detachment.

Skills oriented towards personal accomplishment, on the other hand, mainly concern the evaluation ability, from which results the selection, correct management and valorisation of information. Starting from this vision, the new measure of excellence of the working world is no longer based only on what one is prepared for or experienced in, but "focuses mainly on personal qualities such as initiative and empathy, the ability to adapt and to be persuasive" and therefore on the ability to "work with emotional intelligence" (Goleman, 1998).

Emotional intelligence refers to a set of social and personal skills. This definition includes all those individual characteristics, personality features and skills/competences essential to emerge and succeed; as a matter of fact, Emotional Competence "is a learned ability grounded in emotional intelligence, which results in an excellent professional performance" (Goleman, 1998). 
The model of Goleman's emotional competence structure (1998) summarizes two types of competences, i.e. those personal and social, to which 5 dimensions are related:

1) Personal competence:

1.1. Self-awareness (knowledge about one's own emotions, preferences, resources and intuitions).

1.2. Self-regulation (ability to manage one's own emotions, impulses and resources).

1.3. Motivation (emotional trends that drive or facilitate the achievement of goals).

2) Social competence:

2.1. Empathy (awareness of the feelings, needs and interests of others).

2.1. Social awareness (ability to induce desirable responses in others).

In order to cope with Burnout syndrome, teachers implement coping strategies in an attempt to react to a situation which, if not dealt with properly and in time, could degenerate into psycho-physical illness.

Some studies have found that teachers with a hardy personality (having greater individual resilience) and "a high level of self-efficacy have a low level of Burnout, while teachers with high levels of Burnout live in a negative school climate" (Vianello, 2019). The latter include those people who are strongly exposed to regressive or palliative coping strategies (negative adaptation reactions) such as drinking, smoking, taking psychotropic drugs, resulting from behaviours that deny, minimize, hide or avoid stressful events.

Recent studies, besides investigating the Burnout levels of teachers and their respective risk factors, have also highlighted their well-being levels by analysing the protection factors, i.e. all those personal resources useful to face problems compromising personal well-being and career path (anxiety, irritability and lowered self-esteem), and to guarantee a better psychophysical-affective, relational and social condition (Albanese, Fiorilli, Gabola, Zorzi, 2008).

Hence, we are witnessing an important step that moves from focusing on the discomfort, deficiencies and pathologies of the human being to the promotion of well-being, privileging the interest in the protection factors useful to develop the subjects' capabilities.

Moreover, adopting a positive perspective in teachers' school life means referring to those soft skills useful for positively evaluating one's own life.

Knowing how to understand, use and manage one's own and other people's emotions proves to be fundamental not only when dealing with stress or commitment caused by work, but also and above all in the daily confrontation with students and their parents, colleagues and school manager.

Soft Skills cannot be learned through books; they are acquired throughout personal and work life experiences but can be acquired during a quality educational and training course.

Starting from the premise that good knowledge and skills in the domain of emotional intelligence determines positive effects in communication, stress management and positive climate at school, it becomes essential to plan training programs in the workplace adjusted to teachers, so as to develop emotional and social skills in the school environment.

It is therefore necessary to promote the development of new resources and potentialities so as to increase well-being among them, promoting both person-centred courses aimed at changing the person and facilitating individual growth, and by means of strategies aimed at changing the environmental scenario by 
making the work environment more human, refining communication, relational skills and professional skills (Soft Skills).

"For the purposes of corporate training, the moral is that, if they're given the right tools, people can master the emotional-intelligence capabilities the working world demands" (Goleman, 1998).

\section{BIODANZA SRT: INNOVATIVE EMBODIMENT TRAINING IN THE DEVELOPMENT OF SOFT SKILLS}

Biodanza SRT (Rolando Toro System) was developed in 1960 thanks to Rolando Toro Araneda's personal experience (Chilean psychologist and anthropologist), and is a body-mediated Social Pedagogy that acts on the healthy part of the person, through the interaction of dance/movement, music and group meeting situations inducing Integrated Vivencias (experiences lived with great intensity in the here-now). It is an innovative methodology that, by means of the Embodied Training, develops self-esteem, self-awareness of empathetic and relationship skills, and socialization, by increasing personal empowerment and resilience, and fostering greater skills in adopting appropriate and effective behaviours in different situations of life.

According to the Embodied Cognition construct, cognition is strongly rooted in the body, thus in the action, and is deeply situated/interconnected with the environment (intersubjectivity) in which the organism lives and acts (Welsh, 2006).

In Biodanza, realizing one's own dance means integrating one's own feeling with one's own action, creating a union between the feelings and emotions that animate us and their visible expression of our way of moving in the world.

During a Biodanza session, the group constitutes to all effects an intersubjective space inducing new forms of communication, affectivity and relationship, and plays an essential function: "it is a matrix of rebirth in which each participant finds the affective and permissive control of his or her own change" (Toro Araneda, 2007).

Learning empathetic skills facilitates people's ability to consciously deal with the various situations that arise throughout life. Through a person-centred approach, Biodanza SRT facilitates empathetic and optimistic attitudes (in a positive sense), contributing to the development of the emotional factor and increasing selfawareness, self-regulation, self-esteem, emotional management, empowerment, relational skills, social skills and resilience.

Scientific evidence has shown that Biodanza SRT is a good method to improve emotional intelligence, selfesteem, sense of competence and effectiveness, improving one's own mood (Castañeda, 2009; Villegas, Stuck, 1999).

Biodanza SRT is an important strategy for the prevention of emotional distress with significant variations on Alexithymia (the inability to recognize emotions), becoming a real work of emotional literacy (Giannelli, Giannino, Mingarelli, 2015).

Biodanza is a system that succeeds in changing the stress pattern by replacing it with a harmony pattern. In fact, the outcome of investigations concerning the psychophysiological effects of Biodanza and its relationship with stress (Villegas, Stuck, 1999), have shown that it is effective:

- For the reduction of psychosomatic discomfort (headache, back pain, etc.) due to increased selfregulation; 
- For the positive interpretation of crisis states, resulting in a change in cognitive interpretation;

- For increasing sense of competence, efficiency and self-awareness.

Faced with several possible lines of action, the Biodanza System methodology uses appropriate and specific strategies and methods to develop skills and competences, useful to consolidate a positive approach to Burnout.

Biodanza is a System which is constantly targeted to the expression and integration of human and health potentialities, considering it a precious resource in the actions aimed at preventing the risk factors associated with Burnout.

Biodanza facilitates the learning of new forms of communication, emotional relationships (useful to overcome the depersonalization developed within professional tasks) and of resilience processes making everyone able to resist in a flexible way, without any breakdown, to the adversities of life.

Applying the training-experiential methodology of Biodanza SRT in educational institutions as an operational strategy for emotional, relational and social re-education would reduce those sources of risk that various scientific research works have identified as indicators of Burnout syndrome. It is able to lead to important transformations in the health of workers and to affect the risk factors alternating the work of the teacher, triggering a renewal in the way of approaching one's own and others' lives, creating new relationships, new spaces, new institutional structures, and new ways of living.

The transformative, educational and didactic potential of Biodanza SRT is based on body-mediated training processes, capable of triggering an existential change closely related to the strengthening of social skills, which contribute to personal evolution, develop social relationships and improve the quality of life.

\section{REFERENCES}

Albanese O., Fiorilli C., Gabola P., Zorzi F. (2008), Promozione del benessere negli insegnanti. In C. Guido e G. Verni (a cura di), Educazione al benessere e nuova professionalità insegnante, Bari, Ragusa Grafica Moderna, pp. 85-108.

Castañeda G. M. (2009). "La biodanza como práctica corporal. En relación con la promoción de la salud". Educación Física y Deporte, 28(2), 81-90.

Folgheraiter F., "Introduzione all' edizione italiana". In G. BErnstein e J. Halaszyn, lo operatore sociale. Trento: Centro studi Erickson Editions, 1994.

Gallese V. (2006) Corpo vivo, simulazione incarnata, intersoggettività. Una prospettiva neurofenomenologica, in Neurofenomenologia. Le scienze della mente e la sfida dell'esperienza cosciente, edited by M. Cappuccio, Milano. pp. 293-326.

Giannelli M.T., Giannino P., Mingarelli A., (2015). Efficacia sulla salute di un corso annuale di Biodanza: uno studio empirico con 235 persone. Psicologia della Salute, in the journal of Health Psychology Dossier 1.

Goleman D. (1998). Lavorare con intelligenza emotiva. Come inventare un nuovo rapporto di lavoro. BUR.

Maslach C. (1982), Burnout: The cost of caring. New York: Pretince Hall.

Toro Araneda R. (2007). Biodanza: musica, movimento, comunicazione espressiva per lo sviluppo armonico della personalità. Red Editions, Como, 2013. 
Vianello L. (2019). Gli insegnanti italiani e il burnout. Italian teachers and burnout. Formazione \& Insegnamento XVII - 1 - Supplement.

Villegas A., M. Stuck, y otros (1999): Efectos Psicofisiológicos de un método basado en la música, el movimiento y el encuentro grupal (Biodanza), U.A.I., Buenos Aires. 